\title{
Sol-Gel Synthesis and Characterization of Microporous Silica Membranes
}

\author{
II. Tailor-Making Porosity
}

\author{
Wilma J. Elferink, Balagopal N. Nair, Renate M. De Vos, KlaAs Keizer, ${ }^{1}$ and Henk VerweiJ \\ Inorganic Material Science, Faculty of Chemical Technology, University of Twente, P.O. Box 217, 7500 AE Enschede, The Netherlands
}

Received August 2, 1995; accepted November 13, 1995

\begin{abstract}
Unsupported silica membranes were prepared by acid-catalyzed hydrolysis and condensation of tetraethylorthosilicate. The possibility of tailoring the pore size and porosity of microporous silica membranes was investigated by varying the amounts of reactants. A wide range of porosities of 0 to $30 \%$ could be obtained. Of the varied parameters, the acid concentration in the reaction mixture is of most importance for the variation in porosity. The pore size distribution was calculated from nitrogen adsorption isotherms, by using the H orváth - K awazoe method. This resulted in an average pore diameter of $5 \AA$ with a broad tail up to $10 \AA$. 1996 Academic Press, Inc.
\end{abstract}

Key Words: membrane; silica; microporous; sol- gel.

\section{INTRODUCTION}

Microporous $\left[r_{\text {pore }}<1 \mathrm{~nm}(1)\right]$ silica membranes offer interesting perspectives for gas separation and application in membrane reactors. These membranes consist of a microporous silica top layer on a mesoporous $\gamma$-alumina support. The main purpose of the support is to give strength to the silica top layer, while the silica top layer is responsible for the actual gas separation and permeation. Microporous silica membranes are prepared by a sol-gel modification of mesoporous $\gamma$-alumina membranes. These $\gamma$-alumina membranes are prepared by a slip-casting process of a colloidal solution of boehmite on a porous $\alpha$-alumina support (2). The same process is used to prepare the silica membranes by using the mesoporous $\gamma$-alumina membranes as a support and a polymeric silica sol as the dip solution.

Whether a membrane is suitable for a certain application depends on the membrane properties, such as selectivity and permeability. These characteristics are, in their turn, determined by the structure of the membrane, expressed in terms of porosity and pore size.

\footnotetext{
${ }^{1}$ To whom correspondence should be addressed.
}

It has been reported in the literature that the composition of the synthesis solution influences the structure of the species in the sol (3) and, hence, the final structure of the membrane. This possibility to tailor-make membranes can be of advantage in manufacturing application-oriented membranes with different porosity or pore size. To prepare membranes with predefined properties, it is important to understand the relationship between the synthesis conditions and the resulting structure of the membranes. The first step in this investigation was to study the relationship between the synthesis composition and the structure of the species in the sol. Part of these results have been published in a previous publication [part I (4)]. That article presented a detailed account of small-angle X-ray scattering (SAXS) of silica sols and further calculations of fractal dimensions and monomer/polymer sizes. The next step is to investigate the relationship between the composition of the synthesis solution and the resulting structure of unsupported membranes (gels). Hence it is the aim of this paper to present a more detailed account of the sol-gel synthesis along with characteristics of the resulting unsupported membranes. This article provides within the practical limitations, recipes for arriving at a "predefined" gel porosity.

There are important differences between the processes of preparation of supported and unsupported membranes (gels). Supported membranes are prepared by a dipping procedure and result in silica top layers 60 to $100 \mathrm{~nm}$ thick. Unsupported membranes (gels) are prepared by drying a liquid film of the polymeric silica sol, which results in flakes 0.5 to $2 \mathrm{~mm}$ thick.

The layer formation processes for supported and unsupported membranes $(\sim$ gel $)$ are significantly different on two points (5): The drying time for supported membranes is on the order of seconds, contrary to hours for the gels. During long drying times the condensation reactions will most likely continue, resulting in more branched and hence rigid structures. This hinders interpenetration of the silica polymers, 
resulting in a structure with a higher porosity for the unsupported membranes. For supported membranes, this effect results in structures with lower porosity. On the other hand, support constraints for supported membranes can hinder packing and densification, resulting in structures with a higher porosity for the supported membranes.

These two different conditions on the structural formation of supported membranes and gels make direct predictions, for supported membranes from gel characteristics, difficult. However, we are convinced that the recipes found valid for gels will give a general view, which will be applicable to supported membranes. Further research, however, is necessary to provide accurate recipes for supported membranes.

The silica sols are prepared by the sol-gel method (6). This method has a number of advantages above the conventional powder and melt techniques, such as increased purity and homogeneity, lower processing temperatures, and the possibility of adjusting microstructure (pore size, pore size distribution, and porosity) (3). The structure of the species in the sol can vary from linear polymers (using an acidic catalyst with small amounts of water) to strongly branched colloidal particles (using a basic catalyst with large amounts of water) (6). The possibility to tailor-make can be of advantage in preparing membranes with different porosity or pore size.

The degree of polymerization depends on the ratio of the hydrolysis rate to the condensation rate (8). For controlling the formation of the silica sol-gel structure, the most important parameters are the molar ratio of catalyst to alkoxide, the nature of the catalyst (acidic or basic), and the molar ratio of water to alkoxide (9). But, other parameters, such as the synthesis temperature and solvent concentration, also influence the silica sol-gel structure.

According to Aelion et al. (10), the hydrolysis reaction rate increases linearly with increasing molar ratio of acidic catalyst to alkoxide $\left(r_{\mathrm{a}}\right)$. This has been confirmed by Boonstra and Bernards (11). Higher hydrolysis reaction rates lead to more hydrolyzed and, therefore, more branched polymers, while keeping the reaction time constant.

The literature does not present a clear picture of the influence of the molar ratio of water to alkoxide $\left(r_{\mathrm{w}}\right)$ on the hydrolysis reaction rate. According to Uhlhorn et al. (8) the hydrolysis reaction rate increases with increasing $r_{\mathrm{w}}$, while the condensation rate is retarded. In contrast, Boonstra and Bernards (11) suggest that the differences in hydrolysis reaction rate are minimal. Most authors $(8,11,12)$ agree that the formation of more hydrolyzed species is favored with increasing $r_{\mathrm{w}}$. Partlow and Yoldas (13) did show that the gelling volume of wet gels increases with increasing $r_{\mathrm{w}}$. This reflects an increase in the degree of polymerization. Yoldas (14) states that a higher $r_{\mathrm{w}}$ promotes the formation of a higher ratio of bridging to nonbridging oxygens, thus yielding a stronger oxide network. Hence, with increasing $r_{\mathrm{w}}$,

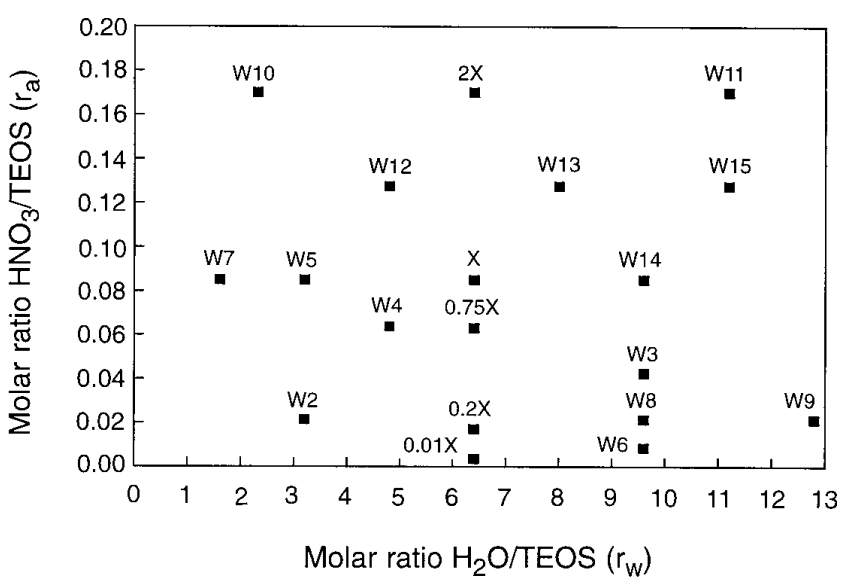

FIG. 1. Compositions of the sol with corresponding sol codes.

the formation of more hydrolyzed species is favored. After condensation, this results in species with a more branched structure. This is confirmed by the viscosity measurements presented by Sakka and Kamiya (12). They reported that, at a constant molar ratio of $\mathrm{HCl}$ to TEOS of 0.01 , linear polymers are formed for $r_{\mathrm{w}}<4$ and branched polymers for $r_{\mathrm{w}}>4$.

The structures of the species in the sols were characterized by SAXS. More details are described in a previous publication [part I (4)]. The structures of the unsupported membranes (gels) were characterized by thermal analysis and nitrogen adsorption/desorption measurements.

\section{MATERIALS AND METHODS}

Silica sols were prepared by carefully adding a mixture of $\mathrm{HNO}_{3}$ (Merck, p.a. grade) and water, using a dropping funnel, to a mixture of ethanol (ethanol absolute, Merck, p.a. grade) and tetraethylorthosilicate (TEOS, Merck, p.a. grade) under vigorous stirring. The reaction mixture was then refluxed for $3 \mathrm{~h}$ at $65 \pm 5^{\circ} \mathrm{C}$ under stirring. The compositions of the sols were chosen in such a way that the silicon concentration, and thus the starting TEOS concentration, was approximately $2 M$. The molar ratio of ethanol to TEOS was kept constant at 3.6. The molar ratios of $\mathrm{HNO}_{3}$ to TEOS $\left(r_{\mathrm{a}}\right)$ and of $\mathrm{H}_{2} \mathrm{O}$ to TEOS $\left(r_{\mathrm{w}}\right)$ were varied. The compositions of the sols and their respective codes are presented in Fig. 1.

To investigate the correlation between sol morphology and structure of unsupported membranes, SAXS experiments were performed using synchrotron radiation (SERC Synchrotron Radiation Services, Daresbury, UK). The scattered $\mathrm{X}$-ray intensities were recorded using a quadrant detector with a camera length of $2.7 \mathrm{~m}$. The spectra obtained were corrected for background and parasitic scattering (4). The sols were kept in closed bottles after synthesis. To minimize aging effects the samples were kept at $-20^{\circ} \mathrm{C}$ until required 


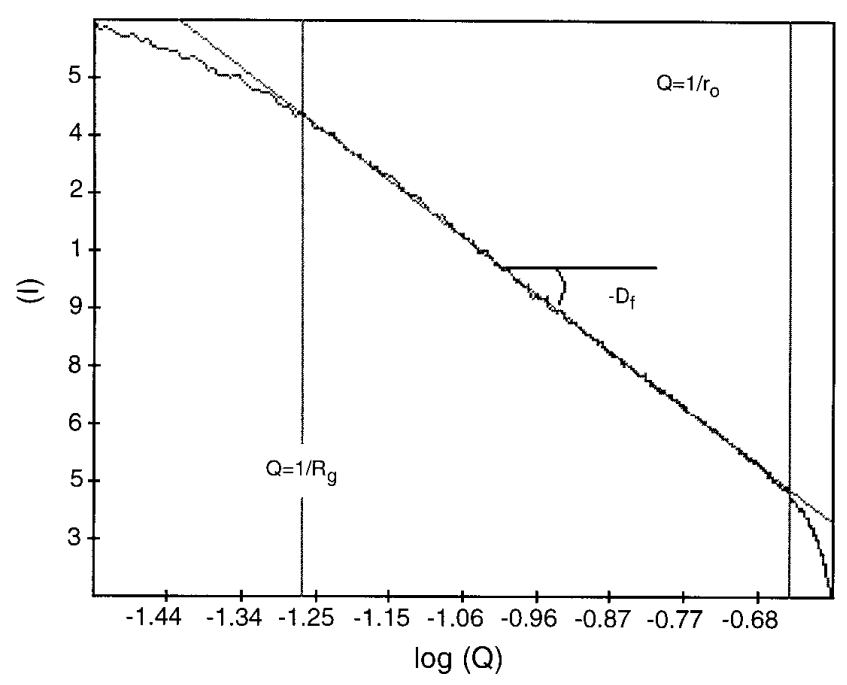

FIG. 2. SAXS spectrum of sol $2 \mathrm{X}$, in which $Q$ is the scattering vector, $I$ is the scattered intensity, $D_{\mathrm{f}}$ is the fractal dimension, $r_{0}$ is the radius of the primary building unit, and $R_{\mathrm{g}}$ is the radius of gyration.

for measurements. Figure 2 presents a typical $\log (I)-$ $\log (Q)$ plot for silica sol $2 \mathrm{X}$, in which $I$ is the scattered intensity and $Q$ is the scattering vector, defined as

$$
Q=\frac{2 \pi}{\lambda} * \sin (2 \theta)
$$

where $\lambda$ is the X-ray wavelength and $2 \theta$ is the scattering angle.

For mass fractals the negative slope of the plot in the fractal region defines the fractal dimension, $D_{\mathrm{f}}$. The lower and upper limits of the fractal region correspond to the size of the primary building units $r_{0}$ and the radius of gyration $\left(R_{\mathrm{g}}\right)(15)$. More details on SAXS theory can be found in the literature $(4,9,16)$.

Unsupported silica membranes were prepared by diluting the sols 19 times by adding ethanol (ethanol absolute, Merck, p.a. grade) to obtain the same concentration as was used in the preparation of supported membranes. These solutions were poured into polypropylene Petri dishes. The liquid films (about $2 \mathrm{~cm}$ high) were dried overnight under ambient conditions in a laminar-flow cupboard. Calcination, when necessary, was done at $400^{\circ} \mathrm{C}$ for $3 \mathrm{~h}$ with a heating and cooling rate of $25^{\circ} \mathrm{C}$ per hour under normal furnace conditions.

The dried unsupported membranes were characterized by thermal analysis on an STA 625 apparatus. The samples were held under flowing air (technical air, $10 \mathrm{ml} / \mathrm{min}$ ) using a heating rate of $2^{\circ} \mathrm{C} / \mathrm{min}$ in the range 25 to $600^{\circ} \mathrm{C}$.

The calcined unsupported membranes were characterized with nitrogen adsorption measurements using a Micromeretics ASAP 2400 . The samples were degassed at $250^{\circ} \mathrm{C}$ for a minimum of $6 \mathrm{~h}$ in vacuo (30 mTorr) before adsorption. The saturation plateau in the isotherm corresponds to the total amount of adsorbed nitrogen per unit weight of the gel. The porosity $(\epsilon)$ can be calculated from this volume of adsorbed nitrogen, according to (9)

$$
\epsilon(\%)=\frac{V_{\mathrm{p}}}{V_{\mathrm{p}}+(1 / \rho)} * 100(\%),
$$

in which $V_{\mathrm{p}}$ is the pore volume $(\mathrm{ml} / \mathrm{g})$, and $\rho$ is the density of the solid phase $(\mathrm{g} / \mathrm{ml})$. A skeletal density of $2.2 \mathrm{~g} / \mathrm{cm}^{3}$ was used for amorphous calcined silica (9). The pore volume is calculated from the adsorbed gas volume [ $\mathrm{ml}(\mathrm{STP}) /$ $\mathrm{g}$, at $1 \mathrm{~atm}$ and $0^{\circ} \mathrm{C}$ ] assuming ideal gas behavior and taking the density of liquid nitrogen, $\rho=0.808 \mathrm{~g} / \mathrm{ml}$, which yields

$$
V_{\mathrm{p}}=V_{\mathrm{ads}} * 1.547 * 10^{-3},
$$

with $V_{\mathrm{p}}$ in ml liquid $\mathrm{N}_{2} / \mathrm{g}$ and $V_{\text {ads }}$ in $\mathrm{ml}(\mathrm{STP}) / \mathrm{g}$.

Adsorption isotherms of microporous unsupported membranes will be of type I (1). For calculation of the pore size/pore size distribution from the isotherms, the HorváthKawazoe method has been used. This method was selected as an attractive way to analyze microporous materials because of its physically plausible basis and the relatively simple calculation method. Details of the adopted fitting procedures have been published elsewhere (9).

\section{RESULTS}

Most of the syntheses (see Fig. 1 for synthesis composition) resulted in translucent sols, which behave as viscous fluids. Sol W11 $\left(r_{\mathrm{a}}=0.17, r_{\mathrm{w}}=11.2\right)$ gelled during synthesis and, therefore, is not a suitable composition for the standard dipping process.

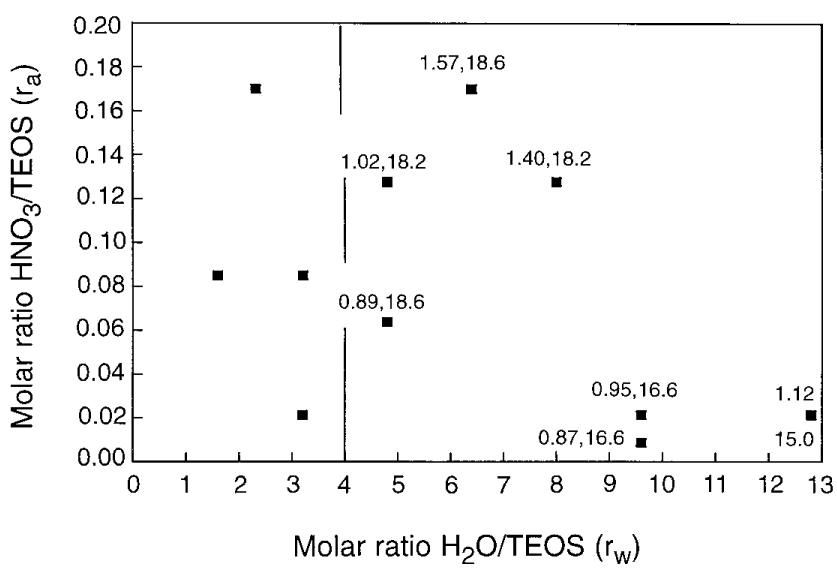

FIG. 3. Effect of sol composition on the values of fractal dimension ( $D_{\mathrm{f}}$, first number) and radius of gyration $\left(R_{\mathrm{g}}\right.$, second number $)$. 


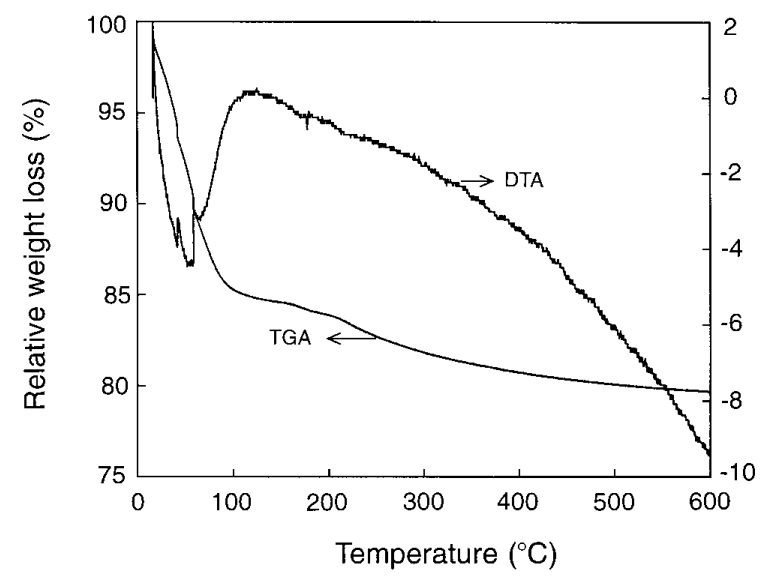

FIG . 4. TGA/DTA plot for sol $X$.

\section{Small-Angle X-Ray Scattering}

A typical curve obtained by SAXS measurements is presented in Fig. 2 for sol $2 \mathrm{X}$, for which $D_{\mathrm{f}}=1.57, R_{\mathrm{g}}=18.6$ $\AA$, and $r_{0}=2.5 \AA$. The values of $D_{\mathrm{f}}$ and $R_{\mathrm{g}}$ for some other sols are shown in Fig. 3. The values for the fractal dimension and the radius of gyration for sols with $r_{\mathrm{w}}<4$ are not presented, because of very low slopes in the fractal region $(<0.8)$. These low values are also found in the literature, but no satisfactory model is available to explain these low values. Within the commonly used model given by Mandelbrot (16) a value of $D_{\mathrm{f}}=1$ indicates linear polymers and values below 1 are not related to any physical structure. Sols with $r_{\mathrm{w}}>4$ show an increase in the value of the fractal dimension with increasing $r_{\mathrm{a}}$ and $r_{\mathrm{w}}$. The value of the radius of gyration (for $r_{\mathrm{w}}>4$ ) decreases for large values of $r_{\mathrm{w}}\left(r_{\mathrm{w}}\right.$ $\approx 10$ ) at low values of $r_{\mathrm{a}}\left(r_{\mathrm{a}} \approx 0.02\right)$. This indicates a decrease in size of the aggregates in the sol (17).

\section{Thermal Analysis}

Dried unsupported silica membranes were characterized by thermal analysis. The result of a typical combined thermographic analysis(TGA)/differential thermal analysis(DTA) experiment is shown in Fig. 4. Up to $600^{\circ} \mathrm{C}$, the DTA curves show no sign of crystallization. For sol $\mathrm{X}$, the total weight loss is about $20 \%$. Up to $150^{\circ} \mathrm{C}$, considerable weight loss is observed, about $15.5 \%$. This can be attributed to the evaporation of adsorbed water and ethanol. Between 150 and $400^{\circ} \mathrm{C}$, mostly removal of organic residues and further polymerization of the silica network take place. At $400^{\circ} \mathrm{C}$ the total weight loss is about $19 \%$. Above $400^{\circ} \mathrm{C}$ a further small weight loss $(\approx 1 \%)$ is related to removal of $\mathrm{OH}$ groups from the surface (3). Similar behavior was observed for most other gels.

The total relative weight loss of the dried gels prepared at a constant $r_{\mathrm{w}}$ of 6.4 increases with increasing $r_{\mathrm{a}}$, as can

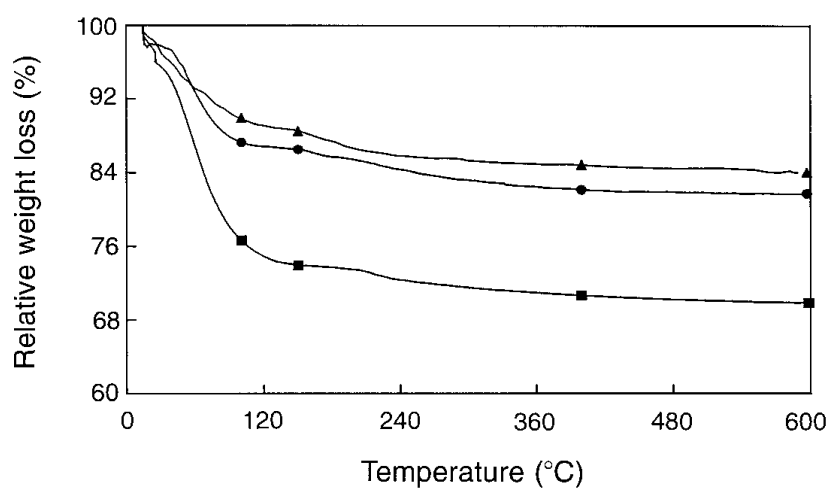

FIG. 5. Effect of molar ratio of $\mathrm{HNO}_{3}$ to TEOS $\left(r_{\mathrm{a}}\right)$ on TGA plots for sols $2 \mathrm{X}(\boldsymbol{\square}), \mathrm{X}(\bullet)$, and $\mathrm{X} / 100(\boldsymbol{\Delta})$, with constant molar ratio of $\mathrm{H}_{2} \mathrm{O}$ to TEOS, $r_{\mathrm{w}}=6.4$.

be seen in Fig. 5. The influence of $r_{\mathrm{w}}$ on the total relative weight loss is less clear. Figure 6 presents the calculated weight loss between 150 and $400^{\circ} \mathrm{C}$ for sols with varying $r_{\mathrm{a}}$ and constant $r_{\mathrm{w}}, r_{\mathrm{w}}=6.4$. With decreasing $r_{\mathrm{a}}$ the relative weight loss between 150 and $400^{\circ} \mathrm{C}$ increases. Figure 7 presents the calculated weight loss between 150 and $400^{\circ} \mathrm{C}$ for sols with varying $r_{\mathrm{a}}$ and $r_{\mathrm{w}}$. The influence of $r_{\mathrm{a}}$ is very clear. The influence of $r_{\mathrm{w}}$ on the calculated relative weight loss between 150 and $400^{\circ} \mathrm{C}$ is less pronounced.

\section{Nitrogen Adsorption}

The calcined unsupported membranes were characterized by nitrogen adsorption measurements. The isotherms for sols $4 \mathrm{X}, 2 \mathrm{X}, \mathrm{X}$, and $0.75 \mathrm{X}$ are given in Fig. 8. They all are type I isotherms. Most of the samples show this type of behavior and are thus microporous (1). Exceptions are samples with $r_{\mathrm{a}} \leqslant 0.021$ and $r_{\mathrm{w}} \leqslant 9.6$, which are nitrogen dense and so do not adsorb nitrogen at $77 \mathrm{~K}$, and sol W9 $\left(r_{\mathrm{a}}=0.021, r_{\mathrm{w}}\right.$ $=12.8)$, which adsorbed nitrogen only at relatively high

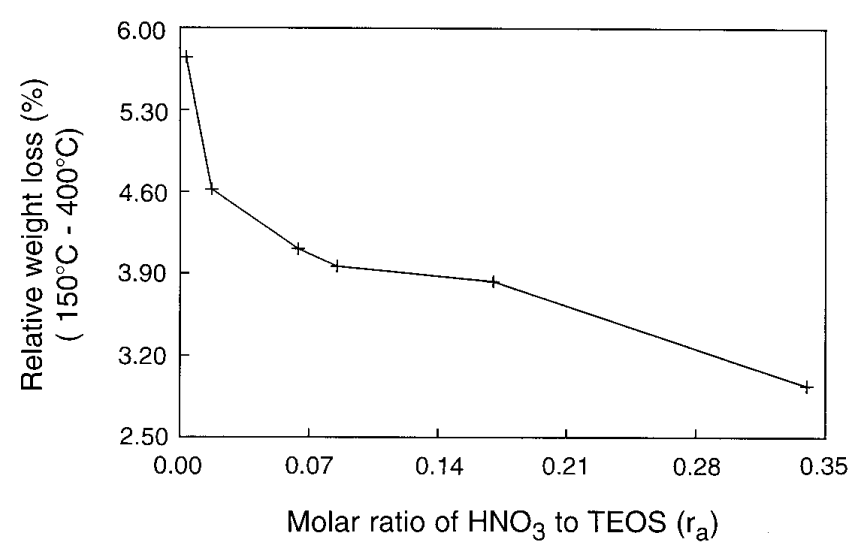

FIG . 6. Effect of molar ratio of $\mathrm{HNO}_{3}$ to TEOS $\left(r_{\mathrm{a}}\right)$ on the relative weight loss $(\%)$ between 150 and $400^{\circ} \mathrm{C}$, with constant molar ratio of $\mathrm{H}_{2} \mathrm{O}$ to TEOS, $r_{\mathrm{w}}=6.4$. 


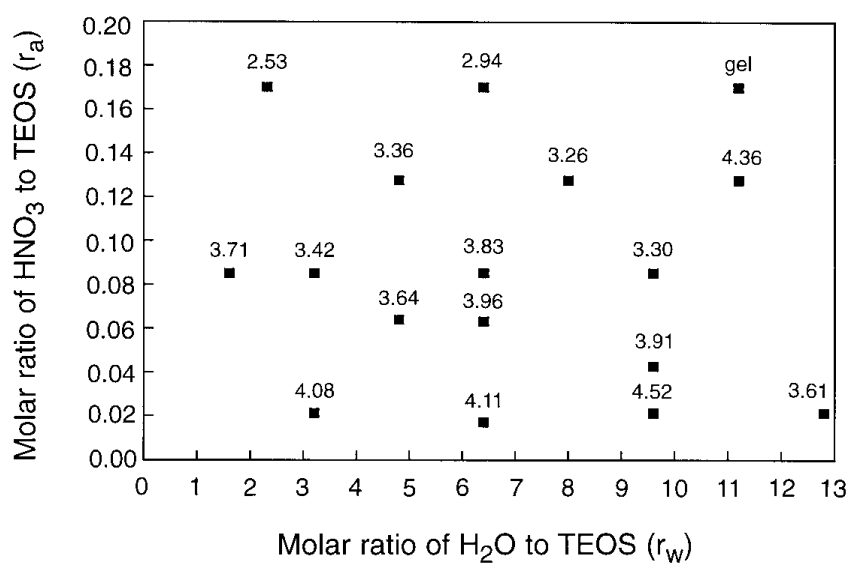

FIG. 7. Effect of sol composition on the relative weight loss (\%) between 150 and $400^{\circ} \mathrm{C}$.

pressures and is hence regarded to be mesoporous. As can be seen in Fig. 9 the porosity increases with increasing $r_{\mathrm{a}}$ at constant $r_{\mathrm{w}}\left(r_{\mathrm{w}}=6.4\right)$. The porosity for the sols can be calculated from the volume of adsorbed nitrogen, as expressed in Eq. [2]. For $r_{\mathrm{w}}>4$, the porosity increases clearly with increasing $r_{\mathrm{a}}$ and tends to increase with increasing $r_{\mathrm{w}}$, as can be seen in Fig. 10. For $r_{\mathrm{w}}<4$, the calculated porosities are surprisingly high, with respect to the low values of $D_{\mathrm{f}}$ obtained with SAXS measurements for these sols. Low values of $D_{\mathrm{f}}$ indicate linear or very weakly branched polymers which would be expected to pack very well and form structures with very low porosities or even nitrogen-dense structures.

The Horváth-Kawazoe method has been applied to data obtained from several samples to calculate the pore size. The peak positions and the width of the peak of the obtained pore size distributions were more or less the same. An example of one of these pore size distributions is shown for sol $\mathrm{X}$ in Fig. 11. The plot shows that the pore size distribution

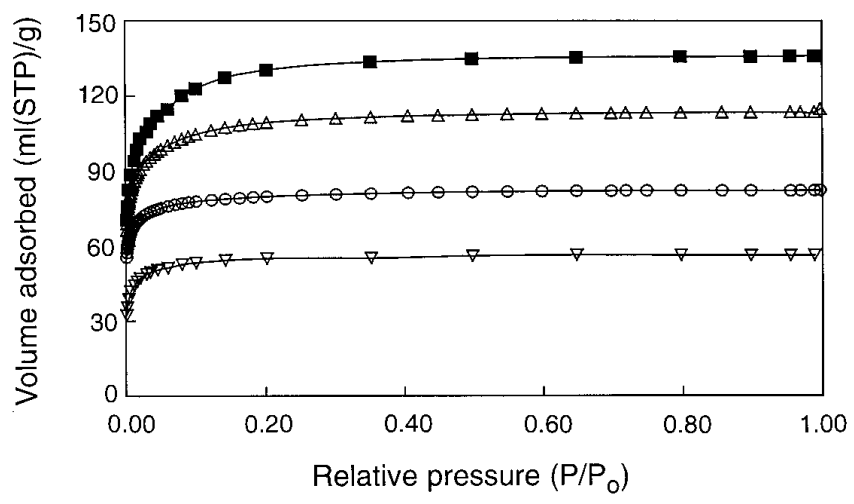

FIG. 8. Effect of molar ratio of $\mathrm{HNO}_{3}$ to TEOS on the adsorption isotherms of sols $4 \mathrm{X}(\boldsymbol{\square}), 2 \mathrm{X}(\triangle), \mathrm{X}(\mathrm{O})$, and $0.75 \mathrm{X}(\nabla)$, with constant molar ratio of $\mathrm{H}_{2} \mathrm{O}$ to TEOS, $r_{\mathrm{w}}=6.4$.

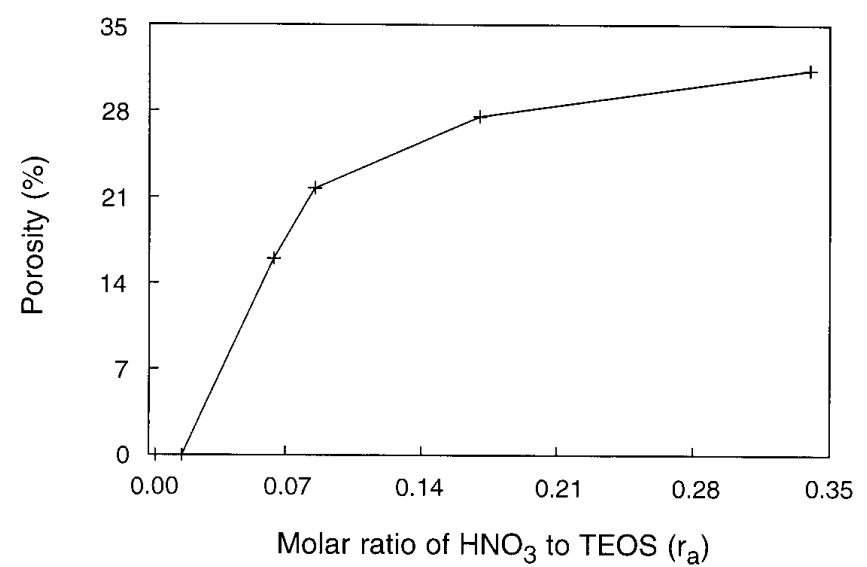

FIG. 9. Effect of molar ratio of $\mathrm{HNO}_{3}$ to TEOS on porosity, with constant molar ratio of $\mathrm{H}_{2} \mathrm{O}$ to TEOS, $r_{\mathrm{w}}=6.4$.

consists of a maximum at $D_{\text {eff }}=0.5 \mathrm{~nm}$ with a broad tail up to around $D_{\text {eff }}=1.5 \mathrm{~nm}$, with a weak maximum at $D_{\text {eff }}$ $=0.75 \mathrm{~nm} . D_{\text {eff }}$ is the effective pore diameter $\left(=2 r_{\mathrm{p}}-d_{\mathrm{E}}\right)$ in which $r_{\mathrm{p}}$ is the calculated pore radius and $d_{\mathrm{E}}$ the diameter of an oxygen atom (18).

\section{DISCUSSION}

To provide recipes for tailor-making silica membranes, the values of $r_{\mathrm{a}}$ and $r_{\mathrm{w}}$ were varied. The boundaries for the range of $r_{\mathrm{a}}$ and $r_{\mathrm{w}}$ are set by practical limitations. These practical limitations are defined as being those synthesis compositions that result in sols that are not suitable for preparation of microporous supported membranes by dipping procedures.

The $r_{\mathrm{a}}$ values have been changed over a wide range from 0.00085 to 0.34 . For a molar ratio of catalyst to alkoxide of 0.021 or smaller, the sols (W2, W6, and W8) yielded nitrogen-dense gels. These gels, however, can still be porous for smaller molecules, e.g., hydrogen $\left(d_{\mathrm{H}_{2}}<d_{\mathrm{N}_{2}}\right)$. Hence, these sols are still considered suitable for preparing microporous supported membranes by the dipping procedure. To the high $r_{\mathrm{a}}$ side no limiting composition was attained, even at $r_{\mathrm{a}}=$ 0.34 the obtained gel was microporous.

The $r_{\mathrm{w}}$ values have been changed over the range 1.6 to 12.8. Limitations were set at high values for $r_{\mathrm{w}}$. At a relatively low values of $r_{\mathrm{a}}$ and a high value of $r_{\mathrm{w}}$, sol W9 ( $r_{\mathrm{a}}$ $\left.=0.021, r_{\mathrm{w}}=12.8\right)$ yielded a mesoporous structure for the unsupported membrane. This makes sol W9 not suitable for the preparation of microporous membranes. Sols with compositions of relatively high values of $r_{\mathrm{a}}$ and high values of $r_{\mathrm{w}}$ were difficult to synthesize, as sol W11 $\left(r_{\mathrm{a}}=0.17, r_{\mathrm{w}}\right.$ $=11.2$ ) did gelate during synthesis. Synthesis compositions with a high $r_{\mathrm{w}}$ value and moderate $r_{\mathrm{a}}$ values $\left(0.06<r_{\mathrm{a}}<\right.$ 0.15 ) produced sols that are suitable for preparing supported 


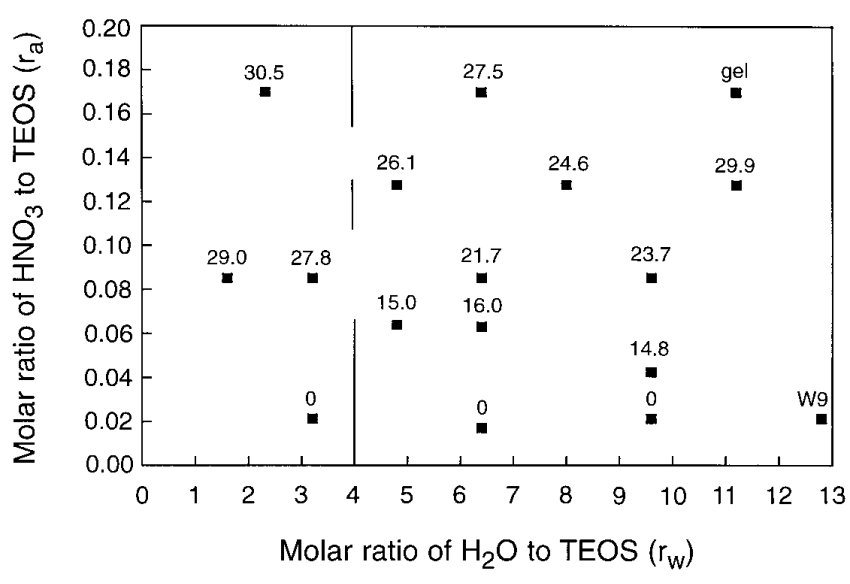

FIG. 10. Effect of sol composition on porosity.

microporous membranes and hence the maximum of $r_{\mathrm{w}}$ was selected for practical considerations to 12.8. No attempt was made to change other parameters or to increase the solvent content, although this could help in avoiding gelation in the present experimental plan.

The influence of the composition of the sol on the structure of the species in the sol was investigated by performing SAXS measurements. In the area $r_{\mathrm{w}} \leqslant 4$, some surprising results were obtained. In this area the SAXS plots show very low values for the fractal slope, $D_{\mathrm{f}}<0.8$. Comparable values for the fractal slope $(<0.8)$ are generally found in the growing stage of the sol (4), indicating that the polymerization reactions are not completed with this low $r_{\mathrm{w}}$ value and within the synthesis time. Surprisingly, these sols result in microporous structures with very high porosity. A logical assumption would be that the partially reacted species in the sol proceed with the condensation reactions during drying, resulting in a more open structure than was expected on basis of the SAXS results.

In the area $r_{\mathrm{w}}>4, D_{\mathrm{f}}$ is increasing with increasing $r_{\mathrm{a}}$ and $r_{\mathrm{w}}$, as shown in Fig. 3. As $D_{\mathrm{f}}$ increases with increasing degree of branching of the polymer (9), it is clear that by increasing $r_{\mathrm{a}}$ and $r_{\mathrm{w}}$, the degree of branching of the species in the sol is increased. This is in accordance with the literature $(10,11)$, where results indicated a linear relationship between $r_{\mathrm{a}}$ and the hydrolysis reaction rate. This leads to more reactions within the same reaction time, resulting in a higher degree of hydrolyzed groups on the species in the sol. After condensation, this results in more polymerized and more branched structures of the species in the sol.

The radius of gyration $\left(R_{\mathrm{g}}\right)$ tends to become smaller for higher values of $r_{\mathrm{w}}\left(r_{\mathrm{w}} \approx 10\right)$ with a low $r_{\mathrm{a}}$ value $\left(r_{\mathrm{a}} \approx\right.$ 0.021 ) (see Fig. 3). Previous results with gels (4) clearly showed that $R_{\mathrm{g}}$ increases with increasing $r_{\mathrm{a}}$. According to Brinker (6), a high $r_{\mathrm{w}}$ promotes the depolymerization of the species. During depolymerization long polymers disintegrate to form several short polymers. This results in lower $R_{\mathrm{g}}$ values and leads to a mesoporous structure as shown for sol W9. This is presumably attributed to the mutually repulsive forces between the disperse phase particles. This will hinder close packing of several short polymers [cf. Ref. (6)].

Changes in the size of the primary building unit seem to be negligible with composition of the synthesis solution. $r_{0}$ was found to be approximately $2.5 \pm 0.5 \AA$ in most of the cases. This value is in accordance with those presented by other authors $(4,9)$. The primary building unit is most likely an oligomer built up from only a very limited amount of monomers since the $\mathrm{Si}-\mathrm{O}$ bond length is $1.6-1.7 \AA$ (9).

As can be seen in Fig. 5, the relative weight loss during heating increases with increasing $r_{\mathrm{a}}$ and constant $r_{\mathrm{w}}\left(r_{\mathrm{w}}=\right.$ 6.4). It is clear from this figure that the largest relative weight loss occurs in the temperature region 0 to $150^{\circ} \mathrm{C}$. As the relative weight loss up to $150^{\circ} \mathrm{C}$ is attributed to the evaporation of water and ethanol (3), the samples with higher $r_{\mathrm{a}}$ contain larger amounts of fluid in their structure (per unit weight of the sample). Therefore, this structure has to be more porous than the structures of samples with lower $r_{\mathrm{a}}$. This conclusion is in accordance with results from the nitrogen adsorption measurements in which samples with increasing $r_{\mathrm{a}}$ show an increase in porosity.

In the range 150 to $400^{\circ} \mathrm{C}$ the relative weight loss decreases with increasing $r_{\mathrm{a}}$ at constant $r_{\mathrm{w}}\left(r_{\mathrm{w}}=6.4\right)$ ( see Fig. 6 ). As a higher $r_{\mathrm{a}}$ leads to a higher degree of polymerization and branching of the polymer, the total number of ethoxy groups in the polymer per unit weight of the sample will decrease. The TGA curves were not notably affected by variation of $r_{\mathrm{w}}$.

From Fig. 9 it becomes clear that the porosity increases with increasing $r_{\mathrm{a}}$ with constant $r_{\mathrm{w}}\left(r_{\mathrm{w}}=6.4\right)$. The same is found in Fig. 10, where the porosity increases for increasing $r_{\mathrm{a}}$ at several values of $r_{\mathrm{w}}$. This was expected as Boonstra and Bernards (16) showed that the rate of hydrolysis increases with increasing $r_{\mathrm{a}}$. According to Aelion et al. (10),

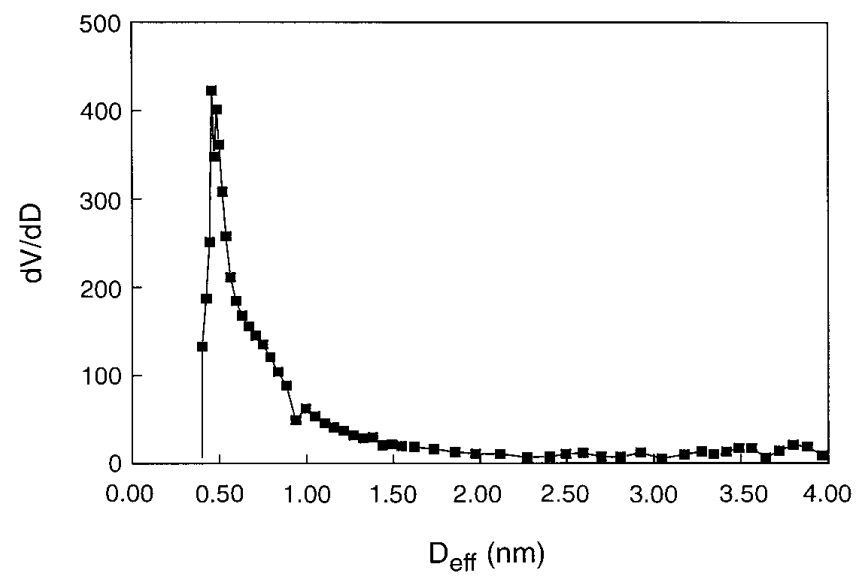

FIG. 11. Differential pore size distribution of sol $\mathrm{X}$ according to the Horvath-Kawazoe model, in which $D_{\text {eff }}$ is the effective pore diameter. 
there is a linear relationship between $r_{\mathrm{a}}$ and the reaction rate of the hydrolysis. Hence the structure of the polymer with the higher $r_{\mathrm{a}}$ will be more polymerized and more branched and, thus, more porous. From Fig. 9, it also becomes clear that with increasing $r_{\mathrm{a}}$ the increase in porosity becomes less. From this figure, it is expected that the porosity becomes constant after a certain saturation point is reached. The samples with $r_{\mathrm{a}} \leqslant 0.0021$ yielded nitrogen-dense gels. Because of the low $r_{\mathrm{a}}$, these structures will most likely consist of linear polymers, which can pack very closely together into dense structures.

The literature is very clear about the influence of $r_{\mathrm{w}}$ on the structure of the gel. For example, Yoldas (14) states that an increase in $r_{\mathrm{w}}$ will promote the formation of a higher ratio of bridging to nonbridging oxygen, yielding a more polymerized and more branched structure. This will lead to a higher porosity. The results presented in Fig. 8 give reason to a more cautious statement. The present set of experiments indicates that, for $r_{\mathrm{w}}>4$, the porosity has a tendency to increase with increasing $r_{\mathrm{w}}$. As already discussed earlier, sols with $r_{\mathrm{w}}<4$ resulted in gels with a surprisingly high porosity.

It also becomes clear from Fig. 10 that small changes in $r_{\mathrm{a}}$ result in relatively large changes in porosity, whereas large changes in $r_{\mathrm{w}}$ result in relatively small changes in porosity. Hence it can be concluded that most of the structures can be tailor-made by a mere variation of $r_{\mathrm{a}}$ alone without resorting to changes in $r_{\mathrm{w}}$. Thus, for tailor-making membranes, changes in $r_{\mathrm{a}}$ have greater influence on the structure than changes in $r_{\mathrm{w}}$.

The results of the SAXS measurements made it clear that the composition of the sol influences the structures of the species in the sol. For $r_{\mathrm{w}}>4$, an increase in $r_{\mathrm{a}}$ as well as in $r_{\mathrm{w}}$ leads to more branched species in the sol. After drying and calcination, the nitrogen adsorption measurements showed that more branched species in the sol result in more porous structures of the unsupported membranes for $r_{\mathrm{w}}>$ 4. For example, the nitrogen-dense samples $\left(r_{\mathrm{a}} \leqslant 0.021\right)$ had a $D_{\mathrm{f}} \approx 1$, indicating linear polymers. More porous gels, like the one prepared from sol $2 \mathrm{X}$, showed a higher $D_{\mathrm{f}}\left(D_{\mathrm{f}}\right.$ $\approx 1.5$ ), indicating a more branched structure. Thus, the structure of the unsupported membranes can be predicted on the basis of the information on the structure of the species in the sol $\left(r_{\mathrm{w}}>4\right)$.

\section{SUMMARY}

To manufacture application-oriented membranes, tight control of porosity and pore size is needed. To provide recipes for preparing unsupported membranes (gels) with a "predefined" structure two synthesis parameters were varied, $r_{\mathrm{a}}$ and $r_{\mathrm{w}}$. This led to the following conclusions.

The initial composition of the sol influences the structure of the species in the sol, in which an increase in $r_{\mathrm{a}}$ and $r_{\mathrm{w}}$ leads to a more branched structure. An increase in $r_{\mathrm{w}}$ at relatively low $r_{\mathrm{a}}$ values leads to a decrease in size of the aggregates in the solution. For $r_{\mathrm{w}}>4$, the influence of the initial composition was also found in the structure of the dried and the calcined unsupported membranes (gels). Again, with increasing $r_{\mathrm{a}}$ and $r_{\mathrm{w}}$, the porosity of the unsupported membranes increases, indicating more branched structures. This leads to the conclusion that the structure of the unsupported membranes can be predicted on the basis of information on the structure of the species in the sol, for $r_{\mathrm{w}}>4$. This is not true for $r_{\mathrm{w}}<4$.

For tailor-making these unsupported membranes, $r_{\mathrm{a}}$ is more important than $r_{\mathrm{w}}$, because a small change in $r_{\mathrm{a}}$ results in a relatively large change in porosity, whereas a relatively large change in $r_{\mathrm{w}}$ results in a relatively small change in porosity. From the results obtained, predictions can be made about the porosity of the unsupported membranes over a wide range from 0 to $31 \%$. The peak position and the width of the pore size distribution stay the same for all gels as characterized with nitrogen adsorption/desorption measurements and calculated by the Horváth-Kawazoe method.

Within practical limitations, the following selection rules for tailor-making microporous unsupported membranes have been established:

1. Nitrogen-dense structures can be obtained at relatively low values of $r_{\mathrm{a}}(\leqslant 0.021)$ and low to moderate values of $r_{\mathrm{w}}(\leqslant 10)$. These structures may be microporous for gases with smaller molecular dimensions, e.g., $\mathrm{He}$ or $\mathrm{H}_{2}$.

2. Relatively moderate porosities, up to $16 \%$, can be obtained with low to moderate values of $r_{\mathrm{a}}\left(0.021<r_{\mathrm{a}} \leqslant\right.$ $0.065)$ and moderate values of $r_{\mathrm{w}}\left(4<r_{\mathrm{w}}<10\right)$.

3. Higher porosities of 20 to $26 \%$ can be obtained with $r_{\mathrm{a}}$ values between 0.065 and 0.15 and moderate values of $r_{\mathrm{w}}$ $\left(4<r_{\mathrm{w}}<10\right)$.

4. Porosities above $26 \%$ can be obtained with $r_{\mathrm{a}}$ values above 0.15 and moderate values of $r_{\mathrm{w}}\left(4<r_{\mathrm{w}}<10\right)$ or with moderate $r_{\mathrm{a}}$ values $\left(r_{\mathrm{a}} \sim 0.13\right)$ and large $r_{\mathrm{w}}$ values $\left(r_{\mathrm{w}}\right.$ $\sim 11$ ).

\section{ACKNOWLEDGMENTS}

The authors thank Professor A. J. Burggraaf, Dr. R. S. A. de Lange, and Dr. B. A. Boukamp for discussions.

\section{REFERENCES}

1. Sing, K. S. W., Everett, D. H., Haul, R. A. W., Moscou, L., Pierotti, R. A., Rouquérol, J., and Siemieniewska, T., Pure Appl. Chem. 57 (4), 603 (1985).

2. Leenaars, A. F. M., "Preparation, Structure and Separation Characteristics of Ceramic Alumina Membranes." Thesis, University of Twente, The Netherlands, 1984.

3. Brinker, C. J., and Scherer, G. W., "Sol-Gel Science: The Physics 
and Chemistry of Sol-Gel Processing." Academic Press, London, 1990.

4. Nair, B. N., Elferink, J. W., Keizer, K., and Verweij, H., J. Colloid Interface Sci. 178, 565 (1996).

5. De Lange, R. S. A., Kumar, K. N. P., Hekkink, J. H. A., van de Velde, G. M. H., Keizer, K., Burggraaf, A. J., Doktor, W. H., van Garderen, H. F., and Beelen, T. P. M., J. Sol-Gel Sci. Technol. 2, 489 (1994).

6. Brinker, C. J., J. Non-Cryst. Solids 100, 31 (1988).

7. Sakka, S., Kozuka, H., and Kim, S.-H., in "Ultrastructure Processing of Advanced Ceramics"' (J. D. McKenzie and D. R. Ulrich, Eds.), p. 159. Wiley, New York, 1988.

8. Uhlhorn, R. J. R., Keizer, K., and Burggraaf, A. J., J. Membr. Sci. 66, 271 (1992).

9. De Lange, R. S. A., “'Microporous Sol-Gel Derived Ceramic Membranes for Gas Separation.', Thesis, University of Twente, The Netherlands, 1993.
10. Aelion, R., Loebel, A., and Eirich, F., J. Am. Chem. Soc. 72, 5705 (1950).

11. Boonstra, A. H., and Bernards, T. N. M., J. Non-Cryst. Solids 108, 249 (1989).

12. Sakka, S., and Kamiya, K., J. Non-Cryst. Solids 48, 31 (1982).

13. Partlow, D. P., and Yoldas, B. E., J. Non-Cryst. Solids 46, 153 (1981).

14. Yoldas, B. E., J. Mater. Sci. 14, 1843 (1979).

15. Boonstra, A. H., and Bernards, T. N. M., J. Non-Cryst. Solids 134, 1 (1991).

16. Mandelbrot, B. B., 'The Fractal Geometry of Nature.' Freeman, New York, 1983.

17. Beelen, T. P. M., Dokter, W. H., Van Garderen, H. F., and Van Santen, R. A., Adv. Colloid Interface Sci. 50, 23 (1994).

18. Lange, R. S. A. de, Keizer, K., and Burggraaf, A. J., J. Porous Mater. 1, 139 (1995). 